REVISTA X, Curitiba, volume 14, n.4,p. 322-339, 2019

\title{
INCLUSÃO, INTERAÇÃO E DEFICIÊNCIA VISUAL: UM RELATO DE DUAS EXPERIÊNCIAS NO PROCESSO DE ENSINO-APRENDIZAGEM COM CEGOS
}

Inclusion, interaction and visual deficiency: a report of two experiences in the teachinglearning process with blind people

\author{
Sweder SOUZA - UFPR ${ }^{1}$ \\ Juscelino Francisco do NASCIMENTO - UFPI/UnB ${ }^{2}$
}

\begin{abstract}
RESUMO: Existem alguns documentos oficias, tais como o Programa Educação Inclusiva: direito à diversidade (2003 a 2007), o Programa de Formação Continuada de Professores na Educação Especial - modalidade à distância (2010) (MELLO, 2011), o Programa de Implantação de Salas de Recursos Multifuncionais (2005 a 2008), entre outros, que trazem orientações aos docentes de diversas áreas do conhecimento, em específico no trato com a comunidade cega ou de baixa visão, mas as lacunas científicas e legais (ainda) permanecem. Portanto, este trabalho visa um debate crítico-reflexivo acerca do processo de ensino-aprendizagem de deficientes visuais, baseados nas questões de inclusão e de interação que subjazem este processo. Dessa forma, serão relatadas duas experiências com ensino-aprendizagem para cegos: uma vivida no âmbito de um projeto intitulado English for Blinds; e a outra no Curso de Letras/Inglês da Universidade Federal do Piauí, na modalidade EAD, no polo de Canto do Buriti, a serem mediadas pela literatura pertinente da área, a fim de que dialogue com o relato aqui exposto.
\end{abstract}

PALAVRAS-CHAVE: Inclusão. Interação. Ensino-Aprendizagem. Cegueira.

\begin{abstract}
There are some official documents such as the Programa Educação Inclusiva: direito à diversidade (2003 to 2007), the Programa de Formação Continuada de Professores na Educação Especial - modalidade a distância (2010) (MELLO, 2011), the Programa de Implantação de Salas de Recursos Multifuncionais (2005 to 2008), among others, that provide guidance to teachers in several areas of knowledge, specifically in dealing with the blind or low vision community, but the scientific and legal gaps remain. Therefore, this work aims at a critical-reflexive debate about the teaching-learning process of the visually impaired, based on the inclusion and interaction issues that underlie this process. Thus, two experiences with teaching and learning for the blind will be reported: one lived within the framework of a project entitled English for Blinds;
\end{abstract}

\footnotetext{
${ }^{1}$ Mestrando em Letras/Estudos Linguísticos da Universidade Federal do Paraná - PPGL/UFPR. Participa do Grupo de Pesquisa em Estudos Críticos e Avançados em Linguagens (GECAL/UnB/CNPq) e do Projeto de Interfaces da Intercompreensão em Línguas Românicas e a promoção do Plurilinguismo (UFPR). O presente trabalho foi realizado com apoio da CAPES - 001/88882.181006/2018-01. E-mail: swedersouza@gmail.com

2 Mestre em Letras pela Universidade Federal do Piauí (UFPI). Doutorando em Linguística pela Universidade de Brasília (UnB). Professor Assistente da UFPI, campus Senador Helvídio Nunes de Barros, Picos-PI. Membro dos Grupos de Pesquisa Linguagem, Escola e Sociedade (LES/UFPI), Grupo de Estudos Críticos e Avançados em Linguagem (GECAL/UnB) e (Socio)Linguística, Letramentos Múltiplos e Educação (SOLEDUC/UnB). E-mail: juscelinosampa@ hotmail.com
} 
REVISTA X, Curitiba, volume 14, n.4,p. 322-339, 2019

and the other in the Course of Letters/English of the Federal University of Piauí, in the modality EAD, in the pole of Canto do Buriti, to be mediated by the pertinent literature of the area, in order to dialogue with the report here exposed.

KEYWORDS: Inclusion. Interaction. Teaching-Learning. Blindness.

\section{INTRODUÇÃO}

O Governo Federal brasileiro e o Ministério da Educação (MEC) lançaram alguns documentos em defesa da inclusão, tais como: o Programa Educação Inclusiva: direito à diversidade (2003 a 2007), o Programa de Formação Continuada de Professores na Educação Especial - modalidade à distância (2010) (MELLO, 2011) e o Programa de Implantação de Salas de Recursos Multifuncionais (2005 a 2008); de publicações, como Diretrizes para a Educação Especial na Educação Básica (2001), Orientação e Mobilidade: conhecimentos básicos para a inclusão do deficiente visual (MACHADO et al. 2003); e de livros, como Ensaios Pedagógicos: construindo escolas inclusivas (BRASIL, 2005, 2006a); Saberes e Práticas da Inclusão (BRASIL, 2006b), que trazem orientações aos docentes de diversas áreas do conhecimento, em específico no trato com a comunidade cega ou de baixa visão, mas as lacunas científicas e legais (ainda) permanecem.

Igualmente, podemos perceber que há um movimento governamental a favor da implementação do novo paradigma de inclusão nas escolas, mesmo que, na prática, toda iniciativa desse ideal ainda dependa de investimentos e ações concretas dentro da sala de aula.

Sabemos também que, embora haja indicações em documentos, tais como: Declaração de Salamanca; a Convenção de Guatemala; e a Lei de Diretrizes e Bases da Educação Nacional (LDB), para que incluamos, nos cursos de licenciaturas, disciplinas que contribuam para a formação de professores no que diz respeito aos novos saberes com relação à inclusão de alunos com necessidades educacionais especiais e novas práticas profissionais, ainda há poucos espaços também em nível superior ${ }^{3}$.

Por questões como estas, necessitamos de investigações na área de ensinoaprendizagem e tecnologia, especialmente com a população de deficientes visuais para

\footnotetext{
${ }^{3}$ Parte deste texto figurou o Projeto de Extensão, homologado pelo Edital PROPPG 01/2014 Homologação de Projetos de Pesquisa e de Desenvolvimento Tecnológico e Inovação, intitulado Tecnologia Assistiva no Ensino de Língua Inglesa como Língua Adicional para Cegos - English for Blinds, desenvolvido na Universidade Tecnológica Federal do Paraná, sob responsabilidade da Prof. ${ }^{\text {a }}$ Dr. ${ }^{a}$ Miriam Sester Retorta, confeccionado junto com os alunos de Letras nele envolvidos.
} 
REVISTA X, Curitiba, volume 14, n.4,p. 322-339, 2019

que possamos não somente incluí-los, com sucesso, nas escolas, mas aumentar e melhorar seu capital social para que eles possam ser bem-sucedidos em uma economia global baseada em informação (GIBSON, 2011, p. 2).

Portanto, este trabalho visa um debate crítico-reflexivo acerca do processo de ensino-aprendizagem de deficientes visuais, baseados nas questões de inclusão e de interação que subjazem este processo. Dessa forma, serão relatadas duas experiências com ensino-aprendizagem para cegos: uma vivida no âmbito de um projeto intitulado English for Blinds; e a outra no Curso de Letras/Inglês da Universidade Federal do Piauí, na modalidade EAD, no polo de Canto do Buriti, a serem mediadas pela literatura pertinente da área, a fim de que dialogue com o relato aqui exposto.

\section{O PROCESSO DE INCLUSÃO}

A visão de Inclusão, que hoje é um movimento mundial caracterizado por processos de mudanças étnicas, sociais e educacionais, vigora, desde meados da década de 1980. Sassaki (1999, p. 41) conceitua a inclusão social da seguinte maneira:

[...] processo pelo qual a sociedade se adapta para poder incluir, em seus sistemas sociais gerais, pessoas com necessidades especiais e, simultaneamente, estas se preparam para assumir seus papéis na sociedade. A inclusão social constitui, então, um processo bilateral no qual, as pessoas, ainda excluídas e a sociedade buscam, em parceria equacionar problemas, decidir sobre soluções e efetivar a equiparação de oportunidades para todos.

Um breve resgate histórico aponta, já nas décadas de 1950 e 1960, nos Estados Unidos, os alunos eram aceitos pelas escolas regulares, ao menos por meio período, devido ao esforço dos pais, que organizaram associações, dando início a ações legais e reivindicando pela educação aos seus filhos. A partir dessas conquistas, mesmo que "pequenas", aparentemente, a inserção das pessoas com deficiência trilhou um caminho em que essas pequenas conquistas tornavam-se e tornaram-se importantes para as mudanças de hoje.

Na década de 1970, alunos com deficiências começaram a ser integrados nas escolas regulares, caracterizando, assim, um momento de mudanças nos paradigmas da sociedade. Foi então que, a partir da década de 1980, houve o surgimento de lutas pelos direitos das pessoas com deficiências.

O mundo, por bastante tempo, estava fechado para mudanças. Por essa razão, a partir de 1981, a Organização das Nações Unidas (ONU) decretou, neste ano, o Ano 
Internacional das Pessoas Portadoras de Deficiências (AIPPD). Nesta época, começou a se perceber que as pessoas com alguma necessidade especial também mereciam os mesmos direitos que asseguravam qualquer outro cidadão.

Já na década de 1990, os movimentos de inclusão tornaram-se de grande impulso. Consolidando este marco importante, aconteceu a Conferência Mundial sobre Necessidades Educativas Especiais, em Salamanca, na Espanha. Em 1994, foi reafirmado o compromisso com a Educação para Todos, momento em que foi reconhecida a necessidade e a urgência, entre diversos direitos, da iniciativa de uma educação inclusiva, baseada em lei e em política, visando que todas as crianças, independente de suas necessidades especiais, fossem matriculadas em escolas regulares.

A princípio, com o uso de rampas, também uma forma de acessibilidade, eles foram ganhando liberdade e acesso às escolas, bares, teatros, igrejas, restaurantes, cinemas, transporte público etc.

O mundo foi se adequando para dar oportunidade a eles. No entanto, mesmo a nossa cultura tem uma pequena experiência em relação à inclusão social, como se vê nas pessoas que ainda criticam a igualdade de direitos e não cooperam com aqueles que "fogem dos padrões" estabelecidos por um determinado grupo. Nesse sentido, e diante destes olhos que não cooperam, nós, pessoas que nos importamos, também somos mal vistos, também somos diferentes.

\section{A DEFICIÊNCIA VISUAL}

Segundo Ochaita e Rosa (1995, p. 183), a cegueira "é um tipo de deficiência sensorial e, portanto, sua característica mais central é a carência ou comprometimento de um dos canais sensoriais de aquisição da informação, neste caso o visual".

Naturalmente, existem consequências a respeito da aprendizagem e do desenvolvimento dos sujeitos com deficiência visual, sendo necessária a elaboração de diferentes sistemas de ensino que possibilitem a transmissão do conhecimento para que a informação chegue de forma adequada a esses.

É por meio da ação sobre um ambiente e da comunicação social que pode ser alcançado o domínio de habilidades mentais que levariam a possibilidade do conhecimento da realidade, segundo as teorias contemporâneas sobre o desenvolvimento psicológico.

Para o desenvolvimento dessas habilidades, é preciso ter em mente, ao ajustadas, que elas de fato cheguem à ação, ou seja, que cheguem aos canais sensoriais, fazendo 
REVISTA X, Curitiba, volume 14, n.4,p. 322-339, 2019

com que o desenvolvimento cognitivo do deficiente visual siga por um caminho que não tem por que ser coincidente com o dos videntes.

As atividades específicas são afetadas pela falta de visão, e talvez a mais importante seja a movimentação no espaço físico. O sistema sensorial mais importante que a pessoa cega possui, para conhecer o mundo, é o sistema háptico ou tato ativo (OCHAITA; ROSA, 1995).

É necessário diferenciar entre tato passivo e tato ativo ou sistema háptico (GIBSON, 1966). Enquanto no primeiro a informação tátil é recebida de forma não intencional ou passiva (como a sensação que a roupa ou o calor produz em nossa pele), no tato ativo, a informação é buscada de forma intencional pelo indivíduo que toca. Assim, pois, no tato ativo, encontram-se envolvidos não somente os receptores da pele e os tecidos subjacentes (como ocorre no tato passivo), mas também a excitação correspondente aos receptores dos músculos e dos tendões, de maneira que esse sistema perceptivo capta a informação articulatória motora e de equilíbrio (OCHAITA; ROSA, 1995).

Gibson (1966) dá destaque para a importância do conhecimento do mundo pelo tato. Quando um cego está explorando com as mãos um objeto estranho, para reconhecê-lo, ocorre algo parecido a quando um vidente olha uma forma complexa e desconhecida para posteriormente desenhá-la.

As mãos, como os olhos, embora de forma mais lenta e sucessiva, movem-se de forma intencional para buscar as peculiaridades da forma e poder, assim, obter uma imagem dela (OCHAITA, ROSA, 1995). Logo, o tato constitui um sistema sensorial que tem determinadas características e que permite captar diferentes propriedades dos objetos, tais como temperatura, textura, forma e relações espaciais.

\section{AS REPRESENTAÇÕES DO CONHECIMENTO EM DEFICIENTES VISUAIS}

As relações a respeito do conhecimento em deficientes visuais é motivo de polêmica no meio dos estudos de psicologia cognitiva. Para um vidente, consideramos que o conceito de uma imagem mental coincide com o da imagem visual, tendo estas diversas formas, não sendo uma imagem única, por exemplo, um cachorro, representamos um cachorro de diversas formas, raças, cores etc., pois temos as representações baseadas em outras mobilidades sensoriais, como a audição, o olfato, a gustação ou até mesmo a propriocepção (OCHAITA, ROSA, 1995). 
REVISTA X, Curitiba, volume 14, n.4,p. 322-339, 2019

Os sujeitos com tal deficiência utilizam uma ampla gama de possibilidades de percepção do mundo, utilizando as modalidades sensoriais de que dispõe.

Ochaita e Rosa (1995) referem-se a um trabalho proposto com adultos, que estudou a capacidade de os cegos compreenderem tarefas de alternação de formas captadas mediante o tato.

A investigação de Carpenter e Eisenberg (1978) constitui um exemplo típico: tratava-se de estimar se a imagem de uma letra ("P" ou "F") era a correta, tanto quando as letras encontravam-se em posição normal como com diferentes ângulos de inclinação. Dado que os cegos de nascença foram capazes de perceber mentalmente a alternação de formas nos eixos horizontal, vertical e oblíquo do espaço euclidiano, cabe inferir que o sistema háptico pode dar lugar a representações mentais de caráter espacial. Outros trabalhos (MILLER, 1975, 1977; PRING, 1982; FERNÁNDEZ, OCHAITA, ROSA, 1988) destacaram a possibilidade de reter, na memória, a curto prazo, a informação apresentada tatilmente. Isto é especialmente relevante para a leitura, já que os cegos podem ter acesso direto ao léxico a partir da codificação tátil, sem ter que passar através de um código fonológico.

Além dessa percepção mental de informação derivada de um código tátil, existe outro fenômeno de grande interesse referente à memória semântica. Foi comprovado que os cegos não apresentam diferenças em relação ao vidente no que compete à codificação semântica de informações, por exemplo, um relâmpago ou uma nuvem, por meio da informação verbal.

Isto se torna especialmente evidente quando a informação é apresentada de forma auditiva (ROSA, 1986) e, naturalmente, não se trata de um traço inerente à carência de visão, senão do resultado de um processo de aprendizagem ao longo do desenvolvimento.

Em primeira instância, podemos duvidar de que pessoas com deficiência visual, e até mesmo com qualquer outra deficiência, possam ser capazes de obter conhecimento, erro que o ser humano até hoje - menos do que antes - acredita. Com o desenvolvimento tecnológico das últimas décadas, e os avanços científicos, temos cada vez mais arcabouços teóricos que desvendam este tabu, e temos cada vez mais convicção de que sujeitos com necessidades educacionais especiais podem, sim, atingir um nível de desenvolvimento intelectual, se não igual, semelhante ao dos videntes ou de quem não apresenta nenhuma deficiência. 
REVISTA X, Curitiba, volume 14, n.4,p. 322-339, 2019

Em suma, a diferença de rendimento entre deficientes visuais versus videntes desaparece ao passo que o processamento de informação adquire uma presença funcional significativa e que se manifesta de forma proposicional ao pensamento e às habilidades, o que leva a crer que a linguagem ocupa, sem dúvidas, um papel significante no funcionamento cognitivo no deficiente visual.

Algumas tarefas, cuja estrutura é concreta - segundo Piaget (1973) - não podem ser resolvidas até que as habilidades estejam completamente desenvolvidas, ou seja, na ausência da visão, requer-se a utilização de outras habilidades mais sofisticadas do que concretas.

\section{LÍNGUA(GEM) E AQUISIÇÃO: ENSINO-APRENDIZAGEM}

Piaget (1973) visa a uma reflexão construtivista sobre a aprendizagem e o desenvolvimento, sendo a aprendizagem a alavanca para o desenvolvimento. Essa perspectiva é considerada maturacionista, visto que aborda o desenvolvimento das funções biológicas com base na aprendizagem.

Com base em Vygotsky (1996), temos a perspectiva sócio-interacionista, sóciocultural ou sócio-histórica, onde a relação entre aprendizagem e o desenvolvimento estão ligadas devido ao ser humano viver em um meio social, sendo essa a principal alavanca para estes dois processos. Sem dúvidas, a aprendizagem e o desenvolvimento andam juntos mesmo, que não em paralelo.

Ao contrário de Piaget (1973), Vygotsky $(1996,1998)$ tece a respeito do desenvolvimento como dependente da aprendizagem, na medida em que se dá o processo de internalização dos conceitos, ora promovidos pelo fator social, principalmente no meio escolar. Para Vygotsky (1996), o fator biológico da espécie não é suficiente para realização de atividades sem a participação de ambientes e práticas específicas que proporcionam a aprendizagem. A ideia de que um indivíduo se desenvolva com o tempo é refutada. Assim, o indivíduo é reconhecido como um ser pensante, que vincula sua ação ao mundo que o constitui culturalmente. Desse modo, a escola é um espaço e um tempo onde este processo é vivenciado, onde o processo de ensino-aprendizagem envolve diretamente a interação entre sujeitos.

A interação e a imbricação destes processos de ensino e aprendizagem podem ser compreendidos quando falamos da Zona de Desenvolvimento Proximal, ou ZDP, que, segundo Vygotsky (1996), seria a distância entre o nível de desenvolvimento real determinado pela capacidade de resolver problemas independentemente - e o nível de 
REVISTA X, Curitiba, volume 14, n.4,p. 322-339, 2019

desenvolvimento proximal - demarcado pela capacidade de solucionar problemas com a ajuda de um parceiro mais experiente.

Seria a aprendizagem que ocorre na ZPD fazendo com que o indivíduo se desenvolva ainda mais - desenvolvimento com aprendizagem na ZDP leva a mais desenvolvimento, por isso dizemos que, para Vygotsky (1996), tais processos são indissociáveis. É justamente na Zona de Desenvolvimento Proximal que ocorre a aprendizagem. A função do professor seria, então, a de favorecer esta aprendizagem, sendo mediador entre o indivíduo e o mundo.

Se nos basearmos na teoria vygotskyana, vemos que esse processo acontece sem a linguagem visual. Trazendo essa teoria ao ensino de Língua Estrangeira, doravante LE, para os cegos, vemos que eles, são tanto capazes de adquirirem uma LE como qualquer outro indivíduo que tenha alguma deficiência auditiva ou física. Claro que esses são alguns dos pontos a serem analisados e que existe muito mais por trás da aquisição da linguagem em deficientes visuais que uma simples hipótese.

Falamos aqui de deficientes visuais adultos, mas todo o processo de aquisição começa enquanto criança, o que depende de vários fatores para que realmente a aquisição se faça. Uma variável como o comportamento materno na infância e o ambiente familiar em que o indivíduo está inserido, o fator socioeconômico, pode influenciar de modo significativo nesse processo.

Esses aspectos foram pesquisados por Dote-Kwan, Hughes e Taylor (1997), os quais visaram avaliar o desenvolvimento das crianças com deficiência visual. A conclusão foi de que o comportamento materno é fundamental no desenvolvimento da criança, podendo produzir ambientes estimuladores para essas crianças, propiciando impactos significativos no que se refere ao desenvolvimento da linguagem.

O processo de aquisição da linguagem é de fato complexo, devido a estar intrinsecamente relacionado com o desenvolvimento global do indivíduo. Por isso, para que seja efetivo, é necessário que os padrões motores, cognitivos e sensoriais estejam funcionando de maneira satisfatória e integrada, de modo que o sistema motor possa agir sobre a articulação dos sons, o cognitivo capacite o indivíduo a compreender as relações entre os acontecimentos e os objetos e, finalmente, o sistema sensorial faça com que o indivíduo perceba os estímulos do ambiente, oferecendo condições para que ele possa agir sobre estes (CUNHA, 1997). 
REVISTA X, Curitiba, volume 14, n.4,p. 322-339, 2019

\section{A TEORIA DAS INTELIGÊNCIAS MÚlTiPlaS: UM ARCABOUÇO DE GRANDE AJUDA}

Segundo a teoria de Gardner (1983), o hemisfério direito do cérebro é o local crucial no processamento espacial das nossas percepções. O trabalho com sujeitos cegos deve proporcionar experiências concretas de aprendizagem, ou seja, trabalhar a inteligência espacial, associando o conhecimento perceptivo com o verbal por meio de descrições claras e explicativas em sala de aula, não refutando a inteligência linguística, pois esta serve de suporte para o entendimento dos deficientes visuais.

O trabalho com uma percepção concreta - inteligência espacial - nos possibilita, então, para o ensino de deficientes visuais, o desenvolvimento da consciência corporal, remetendo a Gardner (1983) a Inteligência corporal-cinestésica, atribuindo a superação de outros comportamentos dos sujeitos com deficiência visual, promovendo, pois, a independência e autonomia - inteligência interpessoal e intrapessoal.

Para o mesmo autor, a inteligência espacial é a capacidade de tirar conclusões precisas a partir da observação de um ambiente. Trata-se, assim, de interpretar e fazer juízos sobre a forma, tamanho, movimento, e as relações entre os objetos ao redor, bem como a capacidade de visualizar e manipular coisas que não são imediatamente visíveis.

No âmbito acadêmico e escolar, damos cada vez menos importância a isso - pois um dia isso foi questão de extremos, sendo motivo para formação e reprovação, servindo de conceito para ditar quem deveria continuar ou se contentar com o que tinha alcançado na trajetória escolar de um sujeito.

Ainda segundo Gardner (1983), todos nós possuímos muitas competências, ou seja, é cada vez mais irrelevante querer saber quem é mais, menos ou nada inteligente. Em vez disso, já que toda pessoa é capaz, devemos perguntar: "De que maneira cada sujeito é inteligente?".

A teoria da inteligência única começou a ser questionada no início dos anos 1980, e em seu lugar surgiram as inteligências múltiplas, sendo identificadas sete nas primeiras pesquisas, incluindo a antiga inteligência única, que é a lógico-matemática ou inteligência racional. Nas pesquisas recentes, foi incluída a inteligência naturalista. Em consequência dessas constatações, os tradicionais testes de inteligência deixam de ter utilidade.

Os testes de quociente de inteligência (QI) sempre foram considerados falhos, porque se limitavam a medir um único aspecto da multiplicidade de habilidades do ser 
REVISTA X, Curitiba, volume 14, n.4,p. 322-339, 2019

humano (GARDNER, 1983; VEJA, 1983; FOLHA DE S. PAULO, 1984; MCKEAN, 1985; GÓES; BARREIRA, 1986; GLOBO CIÊNCIA, 1995). Assim, não mais classificamos as pessoas como tendo "inteligência acima da média", "inteligência média", "inteligência abaixo da média" e "inteligência zero", referindo-nos a um arbitrário valor quantitativo da suposta inteligência única do ser humano.

Quando professores, psicólogos, pedagogos e profissionais que lidam com essa área do conhecimento tentam impor para o sujeito uma única inteligência, estão desconsiderando o potencial que existe no conjunto de caracteres exclusivo que cada pessoa possui, ao passo que quando abrem esse espaço para o sujeito, ele cria sua identidade na construção de conhecimento e se ajudam mutuamente, o que pode ser visto no caso dos deficientes visuais.

Logo, se buscarmos o potencial nas identidades individuais dos sujeitos, significaria descobrir talentos em todos, individualmente, partindo do pressuposto de que ninguém e tão prejudicado que não possua uma habilidade. Se o mais prejudicado dos sujeitos possui uma habilidade, então todos podem aprender cada um com suas peculiaridades.

Não possuímos uma mesma e única habilidade como alguns dos profissionais que tratam dessa área, sejam profissionais clínicos ou professores, classificam os indivíduos, muitas vezes comparando as inteligências com os demais.

As inteligências múltiplas seriam então categorizadas, segundo Gardner (1995), da seguinte maneira: Lógico-matemática: habilidade de usar números efetivamente; Verbal-Linguística: habilidade no uso da palavra oral e escrita; Corporal-Cinestésica: habilidade no uso do corpo todo para expressar ideias e sentimentos; Musical: habilidade para ritmo, melodia ou tom da música; Interpessoal: habilidade de perceber e compreender o interior das outras pessoas; Intrapessoal: habilidade de perceber e compreender o interior de si mesmo; Visuoespacial: habilidade para perceber e usar o mundo visual e espacialmente; Naturalista: habilidade de reconhecer e usar produtivamente a fauna e a flora.

\section{RELATO: PROJETO DE EXTENSÃO ENGLISH FOR BLINDS E EXPERIÊNCIA ACADÊMICA}

Mudanças significativas estão acontecendo no decorrer dos últimos dez anos. No que diz respeito à atenção para com pessoas com necessidades educacionais especiais, essas mudanças estão desafiando profissionais, bem como as próprias pessoas com 
REVISTA X, Curitiba, volume 14, n.4,p. 322-339, 2019

alguma necessidade educacional especial e seus familiares, que são cada vez mais excitadas a pensar e reverem seus valores éticos, suas crenças e seus referenciais teóricos, a fim de que todos possam ter uma vida de qualidade.

Cada vez mais, a sociedade está se tornando inclusiva, adaptando-se à necessidade especial dos cidadãos e descartando atitudes discriminatórias frente às diferenças individuais - Inclusão.

Os cidadãos estão cada vez mais empoderados nos diversos setores de atividade, não aceitando imposições por parte de outras pessoas - Empoderamento.

Os órgãos governamentais, entidades e empresas estão procurando o trabalho em parcerias a fim de solucionar os problemas de falta e escassez de recursos, seja na área da saúde, no âmbito escolar, na educação profissional, empregos etc. - Parcerias.

\section{O PROJETO ENSGLISH FOR BINDS ${ }^{4}$}

No começo de 2013, o então diretor da Associação dos Deficientes Visuais do Paraná (ADEVIPAR), Flávio Roberto Hermany, entrou em contato com o psicólogo Allan Martins Mohr, do Núcleo de Atendimento às Pessoas com Necessidades Específicas (NAPNE), da Universidade Tecnológica Federal do Paraná (UTFPR), em Curitiba, para solicitar um curso de inglês direcionado especificamente à comunidade cega e de baixa visão. À época, os departamentos não dispunham de recursos materiais, humanos e técnicos para aceitar tal desafio ${ }^{5}$.

Em 2014, foi criado, inicialmente, o Ensino de Inglês para pessoas com necessidades educacionais especiais. Esse grupo de estudos era composto pela professora Miriam Sester Retorta e por doze alunos do curso de Letras, os quais desenvolveram juntos a escrita do projeto, a composição de materiais didáticos, os planos de aula, angariaram recursos tecnológicos e físicos etc.

Assim, juntos, concebemos os cursos Inglês Básico 1 para deficientes visuais, ministrado no período de fevereiro a junho de 2014, e o Inglês Básico 2 para deficientes visuais, disponibilizado de agosto a dezembro do mesmo ano.

Tendo em vista a procura do público pelos cursos e nossa ânsia em aprimorar o trabalho, o grupo, até então de estudos, em Tecnologia Assistiva no Ensino de Língua

\footnotetext{
${ }^{4}$ Projeto desenvolvido entre os anos de 2014/2016. Este último pelo Edital DEPEX/UTFPR/2016, intitulado: Letramento Digital e Móvel no Ensino de Inglês Pré-intermediário para Alunos Cegos, coordenado pela Profa. Dra. Miriam Sester Retorta.

${ }^{5}$ Parte deste texto encontra-se no E-book: Teaching English to the Visually-Impaired: a Handbook for Brazilian Teachers, organizado pela Profa. Miriam Sester Retorta, escrito em coautoria com os alunos.
} 
REVISTA X, Curitiba, volume 14, n.4,p. 322-339, 2019

Inglesa como Língua Adicional para Cegos, homologado pela UTFPR, torna-se um Grupo de Pesquisa em Tecnologias, Letramentos e Prática Docente, devidamente registrado no CNPq.

Pelo fato de ocupar posição de suporte teórico e prático para o curso de Letras Português/Inglês, as aulas de inglês para cegos tornaram-se um laboratório de novas experiências e de agires dentro da sala de aula.

Devido à escassez de know-how e de material didático para cegos, os alunos de Letras envolvidos no projeto desenvolveram os próprios materiais a serem utilizados em sala de aula, levando em consideração as necessidades do grupo, o qual, originalmente, contava com vinte e quatro alunos cegos ou com baixa visão.

Evidentemente, passamos por alguns desafios. O primeiro deles foi traçar o objetivo geral do curso, sobretudo pelo fato de que somente doze dos vinte e quatro alunos conseguirem ler em Braille. Além disso, patologias apresentadas pelos alunos em comorbidade como a cegueira, como a esquizofrenia, a surdez, a diabetes, entre outros problemas hematológicos, renais e hepáticos tornaram o desafio de possibilitar o ensino-aprendizagem da língua inglesa para esse público ainda maior.

Outra dificuldade encontrada foi a falta de domínio da tecnologia assistiva para cegos - como Jaws, NVDA ou DoxVox. Muitos deficientes visuais não sabiam manusear essas ferramentas, e poucos, inclusive, conseguiam usar celulares ou tablets. Em virtude desse cenário heterogêneo de desafios, então, decidimos focar nosso curso na produção e na compreensão oral.

Gostaríamos que nossos alunos ficassem fluentes na língua inglesa. Desse modo, optamos por trabalhar a oralidade uma vez que alguns não leem, não escrevem nem em Braille e nem usam os programas específicos para computadores, além do fato de a maioria desses alunos solicitarem que as aulas fossem focadas a oralidade.

Após a decisão do objetivo do curso, veio nosso segundo desafio: como ensinálos. Em virtude dos diversos obstáculos com relação à leitura e à escrita, optamos por elaborar os planos de aulas pautados no ensino de LI em uma abordagem acionista. Queríamos, portanto, que cada aula servisse de palco para a simulação e o ensino de diferentes práticas sociais. $\mathrm{O}$ vocabulário, a gramática e a pronúncia eram ensinados de acordo com os contextos reais que surgiam em aula - pedir comida e bebida em um restaurante, por exemplo.

Durante as aulas, deparamo-nos com outra situação: de que modo ensinaríamos a língua estrangeira, sem utilizar a língua materna? Em uma aula tradicional, utilizamos 
REVISTA X, Curitiba, volume 14, n.4,p. 322-339, 2019

- e muito - recursos visuais em detrimento da tradução de palavras e expressões, contudo, no nosso caso, não podíamos lançar mão de fotos, gravuras e figuras, escrita ou desenho na lousa ou na lousa eletrônica. Em decorrência disso, voltamos aos velhos tempos do método da gramática-tradução e da abordagem audiovisual, a fim de adaptar técnicas "antigas" para o contexto acionista. Assim, tivemos que abandonar, temporariamente, abordagens mais alinhadas com as tendências de ensino de língua estrangeira no Brasil como as de gêneros textuais.

Nisso, almejamos um livro ${ }^{6}$, para professores e para alunos, com as aulas dadas, dentro do enfoque interacionista sociodiscursivo. O terceiro desafio foi, então, como ensinar a língua inglesa para esses alunos. Primeiramente, decidimos investigar as novas tecnologias disponíveis possíveis de serem associadas ao ensino-aprendizagem de LI. Posteriormente, procuramos compreender de que forma as Tecnologias de Comunicação e Informação poderiam ser utilizadas dentro e fora da sala de aula. Além disso, buscamos, também, conhecer as tecnologias assistivas para auxiliar nesse processo.

Assim, a partir dessas experiências, nossa sala de aula tornou-se um ambiente no qual os alunos cegos, os graduandos em pré-serviço e todos os envolvidos nesse processo aprendêssemos e ensinássemos uns aos outros como utilizar as TIC e os programas para cegos a fim de estabelecer a comunicação e a aprendizagem da LI.

Após um ano de curso, o grupo decidiu compilar o material didático pensado, criado e desenvolvido. Assim, nasceu a ideia do e-book e do audiobook. Aquele é um manual para o professor, no qual descrevemos, em detalhes, o que e como trabalhamos cada tópico, enquanto este foi escrito para os alunos cegos. Todas as atividades foram gravadas pelos alunos em áudio e vídeo. $\mathrm{O}$ e-book traz indicações a respeito de como o professor pode utilizar exercícios do audiobook.

Nesse sentido, a experiência adquirida no âmbito do projeto, foi para além da sala de aula, no sentido de que os cursos de Letras, de uma maneira geral, ainda, não estão preparados para lidar com a inclusão. Sobretudo no que tange a prática pedagógica. A teoria acerca de metodologias de ensino, estágios supervisionados etc., não comporta essa necessidade da sociedade. Justamente por conta do projeto é que foi possível ter essa experiência real, gratificante, desafiadora e, de certa forma, autônoma, uma vez que, como descrito, fomos nós, até então graduandos e a professora Miriam, quem

\footnotetext{
${ }^{6}$ Disponível em: http://repositorio.utfpr.edu.br/jspui/handle/1/3085.
} 
REVISTA X, Curitiba, volume 14, n.4,p. 322-339, 2019

desenvolvemos, pensamos, repensamos, discutimos e propomos práticas, até então efetiva para este determinado grupo, de ensino-aprendizagem inclusivas.

\section{CEGUEIRA, INCLUSÃO E UNIVERSIDADE}

A Universidade Federal do Piauí (UFPI), instituída pela Lei 5528/68, está instalada, oficialmente, desde 1971 e, nos dias atuais, conta com cinco campi no estado: O campus sede, em Teresina, e outros quatro, no interior, nas cidades de Parnaíba, Picos, Floriano e Bom Jesus.

Em conformidade com as políticas educacionais engendradas pelo Ministério da Educação (MEC), a UFPI oferece, além dos cursos presenciais, diversos outros na modalidade a distância, em mais de 40 municípios, sendo que dois deles, Juazeiro e Campo Alegre de Lourdes, ficam no estado da Bahia.

Nesses municípios, são oferecidos 15 cursos de graduação e 15 de pósgraduação lato sensu. No entanto, no início deste processo de oferta nessa modalidade, foi feito, a princípio, um projeto piloto, com a oferta do curso de Bacharelado em Administração, no ano de 2006, por meio de uma parceria entre a UFPI, a Universidade Estadual do Piauí (UESPI) e o Instituto Federal de Educação, Ciência e Tecnologia do Piauí (IFPI).

Os alunos que estudam nos cursos da EAD, segundo Nascimento e Silva (2016), são de cidades ou comunidades rurais distantes da capital, vivem da agricultura, de programas sociais ou do serviço público. Ademais, eles divergem, no que diz respeito à idade, em relação aos discentes dos cursos presenciais, uma vez que estes ingressam um pouco mais jovens no ensino superior.

Trataremos, brevemente, acerca da dupla inclusão de uma aluna na universidade. Inicialmente, pelo fato de a EAD oportunizar-lhe o ingresso no curso de Letras/Inglês e, em segundo lugar, pelo fato de essa discente ser deficiente visual.

Por razões de natureza ética, a aluna será identificada apenas por MAMS. Ela tem 36 anos e é natural do estado de São Paulo, mas já reside há alguns anos no interior do Piauí, na cidade de Canto do Buriti, no sul do estado. Trata-se de um município pequeno, com uma população de 20 mil habitantes e fica a $405 \mathrm{Km}$ de Teresina. Essa aluna, na infância, era vidente. No entanto, em virtude de um glaucoma irreversível, ficou cega na juventude.

MAMS, nossa colaboradora da pesquisa, ingressou na Universidade no segundo semestre de 2014, por meio de um exame vestibular específico para a EAD, e formou-se 
REVISTA X, Curitiba, volume 14, n.4,p. 322-339, 2019

no primeiro semestre de 2018, sem ter quaisquer reprovações ao longo do curso, apesar das limitações em virtude da deficiência visual.

Durante o interstício do ingresso à conclusão do curso, a aluna e a universidade tiveram alguns problemas relativos à inclusão da discente. O primeiro impacto foi relacionado a como lidar com a primeira aluna cega do curso de Letras/Inglês. Depois, a como ensinar Inglês a uma aluna que não tinha como aprender com base nas abordagens mais recentes de ensino de Língua Estrangeira, razão pela qual tivemos que nos contentar com os métodos mais tradicionais, da mesma forma que foi feita no projeto da UTFPR.

Por se tratar de um curso oferecido na modalidade a distância, cada polo conta com um tutor presencial e todas as disciplinas, ofertadas semestralmente, têm tutores a distância, que fazem o acompanhamento da turma por meio de uma plataforma on-line, o Sistema Integrado de Gestão de Atividades Acadêmicas (SIGAA). Além desses, há um coordenador de disciplinas, uma coordenadora de tutoria e uma coordenadora geral do curso.

Ao sabermos da existência da aluna, todos os esforços possíveis foram feitos para que houvesse o melhor acompanhamento dela, sem que isso parecesse assistencialismo ou favorecimento individual, uma vez que a discente tem a mesma capacidade cognitiva que os demais alunos.

Contudo, apesar dos esforços empreendidos, não julgamos que eles foram suficientes para atender às necessidades da discente, uma vez que a plataforma, embora tenha a opção "acessibilidade", ainda não está adequada para o público cego ou com baixa visão. Os tutores, presenciais e a distância, não têm formação específica para lidar com alunos com essa deficiência e, por mais que a discente tivesse um computador com o teclado em Braille e, ainda, que sua mãe a acompanhasse nas aulas, sempre aos sábados, a Universidade precisa se adequar às diversas necessidades dos alunos, não apenas no que diz respeito à acessibilidade para cadeirantes ou com mobilidade reduzida, mas para todos os tipos de deficiências, sejam físicas, intelectuais ou sensoriais.

\section{CONSIDERAÇÕES FINAIS}

A diversidade é parte de uma sociedade plural, já que todos os segmentos populacionais representam etnias, raças, culturas, nacionalidades, deficiências, distúrbios etc. No livro Programas de Promoção da Igualdade: Guia de Elaboração 
(Brasília: MTE/Assessoria Internacional, 2000) encontramos que devemos "levar em conta a diferença e a variedade de pessoas e opiniões[...] assumindo que as pessoas são diferentes e a sociedade é formada pelo conjunto destas pessoas" (p. 11). Assim, essas diferenças garantem a sua individualidade e todos os envolvidos devem ser levados em conta, “[...] estabelecendo tratamento sem distinção de qualquer natureza (etnia, ideologia, religião, raça/cor, sexo/gênero, origem social, deficiência, posição econômica, condição de saúde, idade, nacionalidade, naturalidade etc" (p. 11).

No paradigma da Inclusão, a busca do potencial nas identidades individuais deve seguir um novo caminho, o qual deve partir dos professores, profissionais da saúde, familiares, terapeutas, e não menos da sociedade. Precisamos fazer uso alguns princípios na vida, como o empoderamento da autodeterminação e autodefesa, da vida independente, da autonomia, do modelo social da deficiência, da equiparação de oportunidades, da rejeição zero, da cooperação e colaboração, da diversidade humana e das diferenças individuais.

Nos dias atuais, nas instituições, lares etc. existem diversas pessoas com deficiências que ainda são vistos, bem menos do que antes, como incapazes de aprender ou produzir. Antigamente, isso era aceito através de diagnósticos e prognósticos que nossos instrumentais avaliativos e nossos referenciais teóricos mais avançados nos indicavam.

Hoje, pelo paradigma da Inclusão, devido às descobertas e tendo à disposição a teoria das inteligências múltiplas, não temos mais o consentimento das próprias pessoas com deficiência e de outras pessoas socialmente excluídas para continuarmos adotando os critérios de avaliação, as metodologias didáticas e demais recursos educacionais que não mais atendem aos interesses, às aspirações e às necessidades e, acima de tudo, ao potencial até então ignorado de tantas e tantas identidades individuais.

\section{REFERÊNCIAS}

AMIRALIAN, M. L. T. M. Compreender o cego: uma visão psicanalítica da cegueira por meio de desenhos-estórias. São Paulo: Casa do Psicólogo, 1997.

ARMSTRONG, T. Inteligências múltiplas na sala de aula. 2.ed. Porto Alegre: Artmed, 2001.

BRASIL. Lei $n^{o}$ 4.024, de 20 de dezembro de 1961. Fixa as Diretrizes e Bases da Educação Nacional. 
REVISTA X, Curitiba, volume 14, n.4,p. 322-339, 2019

BRASIL. Congresso. Lei $N^{o}$ 5.528. Disponível em $<$ http://www.planalto.gov.br/ccivil_03/leis/1950-1969/L5528.htm. Acesso em 03 de jan. 2018.

BRASIL. Lei $n^{o}$ 5.292, de 11 de agosto de 1971. Fixa as Diretrizes e Bases para o ensino de $1^{\circ}$ e $2^{\circ}$ graus, e dá outras providências.

BRASIL. Constituição 1988. Constituição da República Federativa do Brasil: promulgada em: 5 de outubro de 1988. Art. 205 e 206.

BRASIL. Lei $n^{\circ}$ 7.853, de 24 de outubro de 1989. Dispõe sobre o apoio às pessoas portadoras de deficiência, sua integração social.

BRASIL. Lei $n^{o}$. 8.069, de 13 de julho de 1990. Dispõe sobre o Estatuto da Criança e do Adolescente e dá outras providências.

BRASIL. Portaria $n^{\circ} 1.793$, de dezembro de 1994. Dispõe sobre a necessidade de se complementar os currículos dos cursos de formação docente.

BRASIL. Lei $n^{\circ}$ 9.394, de 20 de dezembro de 1996. Estabelece as diretrizes e bases da educação nacional.

CAMPBELL, L.; CAMPBELL, B.; DICKINSON, D. Ensino e aprendizagem por meio das inteligências múltiplas. 2.ed. Porto Alegre: Artmed, 2000.

CARVALHO, K. M. M.; GASPARETTO, M. E. R. F. VENTURINI, N. H. B. KARAJOSÉ, N. Visão subnormal: orientações ao professor do ensino regular. Editora da Unicamp: Campinas-São Paulo, 1992.

CAVALCANTE, A. M. M. Iluminando os caminhos da pré-escola. Revista do Instituto Benjamin Constant, IBC, Rio de Janeiro, n. 10, 1998.

CUNHA, A. C. B. Promovendo aquisição de linguagem funcional em crianças deficientes visuais: o efeito de um treinamento de mãe em procedimentos de ensino naturalístico. Temas em Psicologia, n. 2, p. 33-57, 1997.

CRECHE. Fiocruz. Projeto Político Pedagógico. Rio de Janeiro: Fiocruz, 2004.

DOTE-KWAN, J.; HUGHES, M.; TAYLOR, S. L.; Impact of early experiences on the development of young children with visual impairments: revisited. Journal of Visual Impairment \& Blindness, 91 (2), p. 131-144, 1997.

FERRETTI, J. S. E. et al.(Orgs). Plano de ensino: rede municipal de ensino de Indaiatuba, Departamento de Ensino Fundamental. Indaiatuba: Secretaria Municipal de Indaiatuba, 2005.

GARDNER, H. Inteligências múltiplas:a teoria na prática. Porto Alegre: Artmed, 1995.

GARDNER, H. Estruturas da mente: A teoria das inteligências múltiplas. Porto Alegre: Artmed, 1994. 
MCKEAN, K. Teorias da inteligência. Diálogo, v. 20, n. 1, p. 65-70, 1987.

NASCIMENTO, J. F.; SILVA, L. F. N. Educação online e mudanças nas práticas comunicacionais de discentes no sertão do Piauí na modalidade EAD. ECCOM, v. 7, n. 14, jul./dez. 2016.

OCHAITA, E; ROSA, A. Percepção, ação e conhecimento nas crianças cegas. In: COLL, C; PALACIOS, J; MARCHESI, Á. (Orgs.) Desenvolvimento psicológico e educação: necessidades educativas especiais e aprendizagem escolar. Porto Alegre: Artes Médicas, 1995. v.3, p.183-197.

RABELLO, E; PASSOS. J. Vygotsky. Disponível em: <http://www.josesilveira.com/artigos/vygotsky.pdf> Acessado em: 5 nov. 2016.

RETORTA, M. S. Teaching English to the Visually-Impaired: a Handbook for Brazilian Teachers. Curitiba: EDUTFPR, 2017.

RIBEIRO, A. M. Curso de Formação Profissional em Educação Infantil. Rio de Janeiro: EPSJV/Creche Fiocruz, 2005.

SASSAKI. Romeu, K. Inclusão: Construindo uma Sociedade para Todos. WVA, Rio de Janeiro, 1999.

SUPERDOTADOS: Como tratar estas crianças tão especiais. Globo Ciência, v. 5, n. 53, p. 28-34, dez. 1995.

SOUZA, S. Inclusão e Interação: perspectivas. Minas Gerais: Portal Educação, Coluna Pedagogia, 21 de Out., 2015.

STAINBACK, Susan, STAINBACK, William. Inclusão: Um guia para educadores. Porto Alegre: Artmed, 1999.

UNESCO. Declaração de Salamanca e linha de ação sobre necessidades educativas especiais. Espanha: UNESCO, 1994. Disponível em: <http://portal.mec.gov.br/seesp/arquivos/pdf/salamanca.pdf>. Acesso em: 10 set. 2017.

VASCONCELlOS, V.; VALSINER, M. R. Perspectivas co-construtivistas na educação. Porto Alegre: Artes Médicas, 1995.

VYGOTSKY, L. S. A formação social da mente. Rio de Janeiro: Martins Fontes, 1996.

VYGOTSKY, L. S. Pensamento e Linguagem. Rio de Janeiro: Martins Fontes, 1998. 